\title{
Treatment of pesticide intermediate industrial wastewater using hybrid methodologies
}

\author{
Sindhu Akinapally ${ }^{1}$ Bhagawan Dheeravath ${ }^{1} \cdot$ Kiran Kumar Panga $^{1} \cdot$ Himabindu Vurimindi ${ }^{1} \cdot$ Srinivasulu Sanaga $^{2}$
}

Received: 24 October 2020 / Accepted: 25 February 2021 / Published online: 14 March 2021

(c) The Author(s) 2021

\begin{abstract}
Abatement of water pollution is being a major concern to be dealt with, as the scarcity of water for basic needs of human beings is increasing drastically. As a part of diminishing water pollution, treatment of industrial wastewater prior to disposal plays a paramount role. Due to the typical characteristics of pesticide, intermediate industrial waste water the treatment is also challenging issue. In this study three different sequential methodologies (Methodology-I: combined rotavapour distillation, fenton and anaerobic biological process, Methodology-II: combined rotavapour distillation, photo fenton and anaerobic biological process, Methodology-III combined coagulation, fenton, electro oxidation and anaerobic biological process) has been evaluated for the treatment of pesticide intermediate industrial wastewater. Among the three sequential methodologies opted in this study for the treatment of pesticide intermediate industrial wastewater, percentage removal of COD was 95\% in methodology-1 (i.e. combined rotavapor distillation, fenton and anaerobic biological treatment).
\end{abstract}

Keywords Pesticide intermediate industrial wastewater $\cdot$ Chemical oxygen demand $\cdot$ Rotavapor distillation $\cdot$ Fenton process $\cdot$ Photo fenton $\cdot$ Anaerobic biological treatment

\section{Introduction}

Nowadays prevention of water resources from getting polluted is being a major concern. Surface water is being polluted by industrial untreated wastewater discharge into nearby water bodies, as they do not meet the dischargeable limits. Surface water bodies are also polluted by many other wastes as they are being easy dump yards for everyone to dispose their wastes generated. Finally, all the water bodies are transforming into toxic and hazardous water resources. In order to protect our water resources it is mandatory to reduce the water pollution by treating the wastes before disposal. Industrial wastewater treatment plays a major role in preventing pollution of water resources (Haline et al. 2018). Pesticides usage cannot be avoided as they are of major importance in agriculture for pest control, in order to

Himabindu Vurimindi

drvhimabindu@jntuh.ac.in

1 Centre for Environment, Institute of Science and Technology, Jawaharlal Nehru Technological University Hyderabad (IST-JNTUH), Hyderabad, India 500085

2 Department of Civil Engineering, JNTUHCEH, Hyderabad, India 500085 improve food crop productivity (Smedt et al. 2015; Carlosa 2008). Inspite of their advantages, they also cause severe pollution which may become bio accumulative (Rhind 2002; Valickova et al. 2013) and even enter our food chain causing harm to human health. So there exists an alarming need to treat this pesticide intermediate industrial waste water properly before discharging them into nature.

Among various industrial wastewaters pesticides intermediate industrial wastewater has typical characteristics due to the presence of high amounts of organic and inorganic compounds. Generally, pesticide intermediates are chemically stable and they cannot be mineralized so easily. Due to their toxicity to microbes, pesticide intermediate wastewater cannot be treated biologically without undergoing any prior pre-treatment by physiochemical methods (Chen et al. 2007; Lapertot and Ebrahimi 2007). The major challenges in treating the pesticide intermediate industrial waste water are its recalcitrant characteristics, toxicity to microbes, high COD, high TSS and highly acidic conditions (Wong 2004; Sadeghi et al. 2013). For treating this kind of waste water conventional processes like adsorption, coagulation, sedimentation are not sufficient as they produce lots of sludge, high operational costs, less removal and the generation of secondary pollutants (Zhang and Dong 2019). Direct conventional 
biological treatment cannot be performed effectively due to toxicity to microbes.

Pesticide intermediate industrial waste water can be treated effectively by advanced oxidation processes as they are mainly based on hydroxyl radicals which are highly non selective to wide range of organics (Malato and Blanco 2002; Barbusiński 2015). Therefore, AOP's can be preferred to treat various types of pesticide industrial wastewater. In recent studies, treatment of real industrial wastewater from petrochemical sector has been treated using hydrodynamic cavitation (HC) in combination with other AOPs at $70 \mathrm{~L}$ capacity. Combined operation of $\mathrm{HC}+$ Fenton $+\mathrm{O}_{2}$ injection at $\mathrm{H}_{2} \mathrm{O}_{2}$ loading of $15 \mathrm{~g} / \mathrm{l}$ and Fenton molar ratio of $1: 20$ was reported to result in 63\% COD reduction during $180 \mathrm{~min}$ of treatment (Joshi and Gogate 2016). Photo fenton was used for the treatment of oil refinery waste water treatment with an initial COD of $3200 \mathrm{mg} / \mathrm{l}$ of which $75 \%$ was removed by photo fenton process (Mohadesi and Shokri 2019).

In recent past, the treatment of wastewater contaminated with fipronil pesticide has been carried out using electro oxidation in which graphite electrodes has been used. COD removal of $79 \%$, was obtained at $\mathrm{pH} 9$ and current density of $7.5 \mathrm{~mA} / \mathrm{cm}^{2}$, Thangamani et al. (2012). A scheme of treatments coagulation-flocculation-sedimentation (CFS) and Fenton has been used to treat the paper and pulp waste water. By using these coagulation-flocculation-sedimentation (CFS) and Fenton processes sequentially $61 \%$ of COD removal was obtained at an alum dosage of $750 \mathrm{mg} / \mathrm{l}, \mathrm{pH} 3$ and settling time of $60 \mathrm{~min}$, Grötzner and Melchiors (2018).

Vacuum evaporation followed by reverse osmosis process had been used to treat wastewater containing surfactant materials. By treating with vacuum distillation COD reduced from 8400 to $1100 \mathrm{mg} / \mathrm{l}$, but as it was not below dischargeable limits further reverse osmosis was performed which could reduce the COD from 1100 to $100 \mathrm{mg} / \mathrm{l}$ (Haaz and Fozer 2019).

These were the recent studies in which AOP's has been used individually to treat various kinds of pesticide and other industrial waste water, but not resulted in satisfactory results. In some studies individual EO itself yielded moderately high $\%$ of COD removal, but the effluents that have been treated in this study has very high COD (i.e. $90,000 \mathrm{mg} / \mathrm{l}$ ) and recalcitrant in nature which led to the usage of combined treatment technologies to get high percentage removal of COD.

\section{Materials and methods}

\section{Waste water}

Pesticide intermediate industrial waste water sample has been collected from pesticide intermediates industry located at Hyderabad, Telangana, India. The physicochemical characterization of wastewater samples has been carried out using "standard methods for the examination of water and wastewater 21st addition-2005, APHA" (Jotin et al. 2012; Bhagawan et al. 2017). The initial characterization of the sample has been given in Table 1 .

\section{Methodology}

Various combined methodologies had been opted for the treatment, as a single approach may not be effective for the wastewater treatment (Boczkaj et al. 2018).

\section{Methodology 1: combined Rotavapour distillation, fenton process and anaerobic biological treatment for the treatment of pesticide intermediate industrial waste water}

Rotavapour distillation of pesticide intermediate industrial wastewater was carried out by taking $250 \mathrm{ml}$ sample in a round bottomed flask and attached to the reactor such that it immerses slightly in the water bath which was set at $100{ }^{\circ} \mathrm{C}$ and this flask with sample was rotated at an rpm of 45 . At the receiver end another round bottomed flask was clamped to the reactor in order to collect the condensate. A vacuum pump was attached to the specified port and cooling water was also pumped into the condenser. Thus the $250 \mathrm{ml} \mathrm{sam}$ ple was distillated for $60 \mathrm{~min}$. The slurry remained in the flask was collected and analysed. Thereafter the collected distillate or condensate was further treated by fenton. Batch mode experiments of fenton on this distilled sample had been carried out in a $500 \mathrm{ml}$ reactor with the working volume of $250 \mathrm{ml}, \mathrm{pH} 3$, reaction time was varied from 30 to $240 \mathrm{~min}(30,60,90,120,150,180,210 \& 240 \mathrm{~min})$ and the dosages of fenton reagents calculated theoretically for $250 \mathrm{ml}$ of sample as $\mathrm{FeSO}_{4} .7 \mathrm{H}_{2} \mathrm{O}$ of $0.027 \mathrm{~g}, \mathrm{H}_{2} \mathrm{O}_{2}$ of $0.9 \mathrm{ml}$ were added and kept in a orbital shaker at room temperature for $240 \mathrm{~min}$ by collecting samples at an interval of $30 \mathrm{~min}$. As the pre treatment with physico chemical methods makes the effluent amenable for biological treatment (Chen et al. 2007; Zhang and Dong 2019; Lapertot and Ebrahimi 2007).

Table 1 Initial characterization of pesticide intermediate industrial wastewater sample

\begin{tabular}{lll}
\hline S. no. & Parameters & Concentrations \\
\hline 1 & Chemical oxygen demand (COD) & $90,000 \mathrm{mg} / \mathrm{l}$ \\
2 & $\mathrm{pH}$ & 1.29 \\
3 & Electrical conductivity (EC) & $103.8 \mathrm{~ms} / \mathrm{cm}$ \\
4 & Chlorides & $36,159 \mathrm{mg} / 1$ \\
5 & Sulphates & $1,685 \mathrm{mg} / \mathrm{l}$ \\
6 & Total Solids (TS) & $75,500 \mathrm{mg} / \mathrm{l}$ \\
7 & Total suspended solids (TDS) & $55,000 \mathrm{mg} / \mathrm{l}$ \\
\hline
\end{tabular}


This effluent from combined rotavapor distillation and fenton process was further treated by biological treatment (anaerobic digestion) with contact time of 5 days to obtain a better efficiency. $\mathrm{pH}$ was adjusted to 6.5. Anaerobic sludge from the UASB reactor of a local municipal wastewater treatment plant located at HMWWS (Hyderabad Metropolitan Water Supply \& Sewerage Board, Amberpet) was used as inoculums (Vijaya Krishna et al. 2017).

\section{Methodology 2: combined Rotavapour distillation, photo fenton process and anaerobic biological treatment} for the treatment of pesticide intermediate industrial waste water

In this methodology, after treating the sample with rotavapor distillation, the condensate obtained was further treated with photo fenton process. Photo fenton process was performed in a cylindrical photo-reactor with a total volume of $1 \mathrm{~L}$ in which working volume was $500 \mathrm{ml}$. The source used for UVirradiation was a low pressure mercury vapour lamp of 250 watts with maximum emission at a wave length of $365 \mathrm{~nm}$ (Fig. 1). This lamp is enclosed within the quartz tube. A magnetic stirrer was placed at the bottom of reactor for the proper homogenization of sample.

During photo fenton process the $\mathrm{pH}$ of the sample was adjusted to 3 using $0.1 \mathrm{~N} / 1.0 \mathrm{~N} \mathrm{HCl}$ or $0.1 \mathrm{~N} / 1.0 \mathrm{~N} \mathrm{NaOH}$ solutions and the dosages of fenton reagents calculated theoretically as $\mathrm{FeSO}_{4} .7 \mathrm{H}_{2} \mathrm{O}$ of $0.054 \mathrm{~g}, \mathrm{H}_{2} \mathrm{O}_{2}$ of $1.8 \mathrm{ml}$ were added to the sample. Then the reaction was carried out for

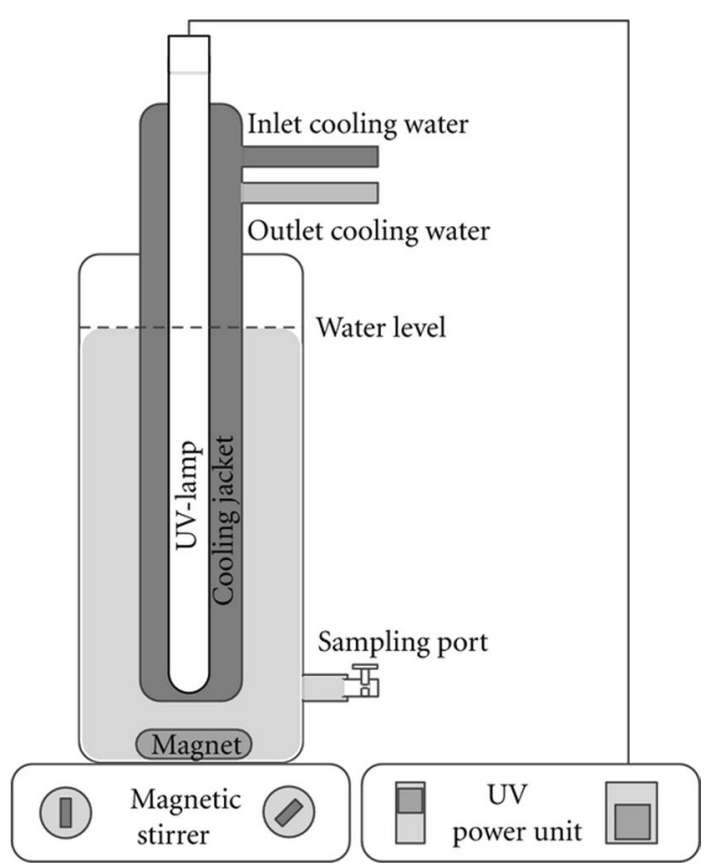

Fig. 1 Schematic diagram of photo fenton reactor
$240 \mathrm{~min}$ by taking samples at an interval of $30 \mathrm{~min}(30,60$, $90,120,150,180,210 \& 240 \mathrm{~min})$.

The effluent from this Combined Rotavapour distillation and photo fenton process was further treated with biological treatment (anaerobic digestion) for a contact time of 5 day.

\section{Methodology 3: combined coagulation, Fenton,} electro oxidation and anaerobic biological treatment for the treatment of pesticide intermediate industrial waste water

The waste water sample was initially treated using coagulation with alum. Coagulation was carried out in a $1000 \mathrm{ml}$ beaker with $500 \mathrm{ml}$ as working volume and $\mathrm{pH}$ was adjusted to 7 . After the addition of coagulant the beaker was placed in Jar test apparatus stirred at $150 \mathrm{rpm}$ for $30 \mathrm{~min}$, then sample was allowed settle for $60 \mathrm{~min}$ and then the supernatant was analysed. In this study dosages of alum are varied from 0.125 to $0.375 \mathrm{~g}$ to get an optimum coagulant dosage. This sample treated with optimum coagulant dosage was further treated with fenton by adding theoretically calculated fenton reagent dosages $\left(\mathrm{FeSO}_{4} \cdot 7 \mathrm{H}_{2} \mathrm{O}\right.$ of $0.04 \mathrm{~g}, \mathrm{H}_{2} \mathrm{O}_{2}$ of $1.4 \mathrm{ml}$ ). The effluent from this combined coagulation and fenton treatment was further treated by electro oxidation, during this the operational conditions were, $\mathrm{pH} 7$, working volume was $200 \mathrm{ml}$, SS-SS electrodes $(100 \mathrm{~mm} \times 50 \mathrm{~mm} \times 2)$, constant voltage of $8 \mathrm{~V}$, current was varied from 4 to 6 Amps and the reaction time was varied from 10 to $60 \mathrm{~min}$ (10, 20, 30, 40, 50 and $60 \mathrm{~min}$ ). The sample treated at optimum reaction time was further treated with biological treatment (anaerobic digestion) for a contact time of 5 day.

\section{Results and discussions}

The initial characterisation of pesticide intermediate industrial wastewater sample was represented in Table 1.

\section{Methodology 1: combined Rotavapour distillation, fenton process and anaerobic biological treatment for the treatment of pesticide intermediate industrial waste water}

Initially, the sample with initial COD 90,000 mg/l, was treated with rotavapor distillation in which, $62 \%$ removal of COD was obtained, thereafter this effluent was treated by fenton in which COD removal of $70 \%$ was obtained at an optimum reaction time of 180 min (Figs. 2, 3). After $180 \mathrm{~min}$ the rate of removal of COD was very less hence inorder to avoid excess costs the reaction time was optimised to $180 \mathrm{~min}$. The overall percentage removal of COD was increased from $62 \%$ in rotavapour distillation to $88 \%$ in combined rotavapour distillation and fenton process. 


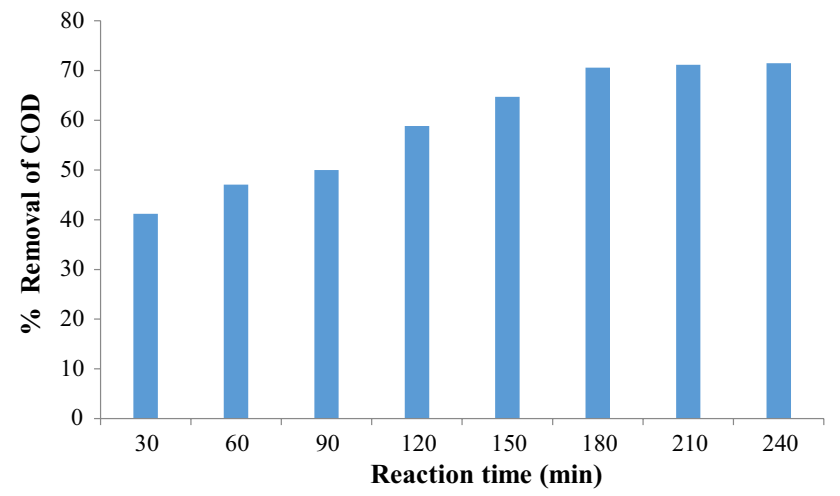

Fig. 2 Percentage removal of COD in Fenton after distillation. Experimental conditions: $\mathrm{FeSO}_{4}$ concentration $(\mathrm{mg} / \mathrm{L})$ : $0.027 \mathrm{~g}, \mathrm{H}_{2} \mathrm{O}_{2}$ concentration: $0.9 \mathrm{ml}, \mathrm{pH}: 3$, initial COD: $34,000 \mathrm{mg} / \mathrm{L}$, working volume: $250 \mathrm{ml}$

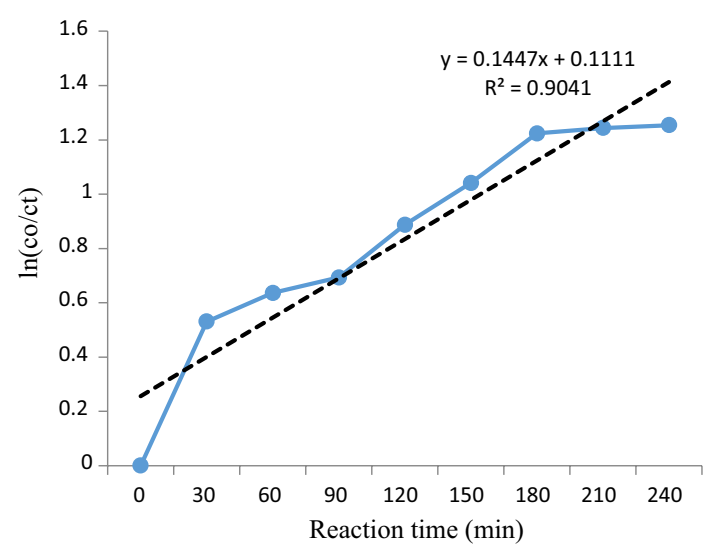

Fig. 3 Kinetics of C.O.D removal in Fenton after distillation

Finally, the effluent from combined rotavapor distillation and fenton process was treated by using anaerobic biological treatment. The percentage removal of COD in biological process was $55 \%$. The overall percentage removal of COD has been increased to $95 \%$.

\section{Methodology 2: Combined Rotavapour distillation, photo fenton process and anaerobic biological treatment for the treatment of pesticide intermediate industrial waste water}

After treating the pesticide intermediate industrial wastewater with rotavapor distillation, further the distillate was treated by photo fenton process. In this photo fenton process after rotavapor distillation COD removal of $76 \%$ was obtained at an optimum reaction time of 180 min (Figs. 4, 5 ). The overall percentage removal of COD was increased from $62 \%$ in rotavapour distillation to $91 \%$ in combined rotavapour distillation and photo fenton process.

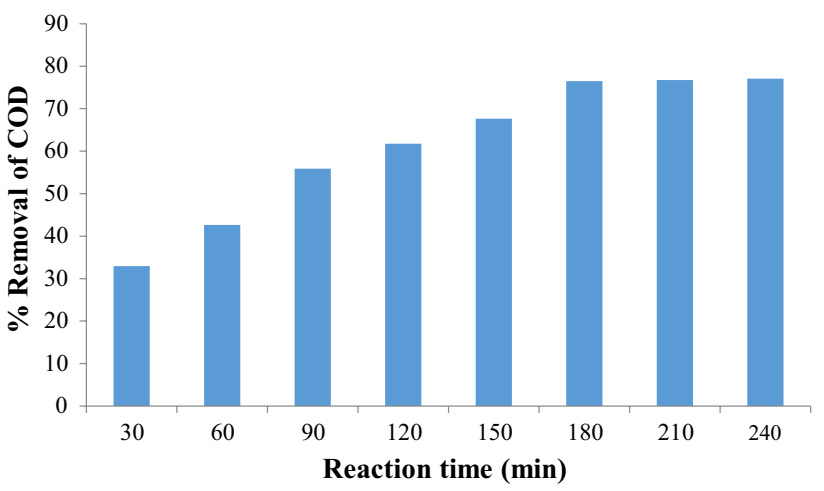

Fig. 4 Percentage removal of C.O.D. in photo fenton after rotavapour distillation. Experimental conditions: $\mathrm{FeSO}_{4}$ concentration (mg/L): $0.054 \mathrm{~g}, \mathrm{H}_{2} \mathrm{O}_{2}$ concentration: $1.8 \mathrm{ml}, \mathrm{pH}$ : 3, initial C.O.D: $34,000 \mathrm{mg} / \mathrm{L}$, working volume: $500 \mathrm{ml}$

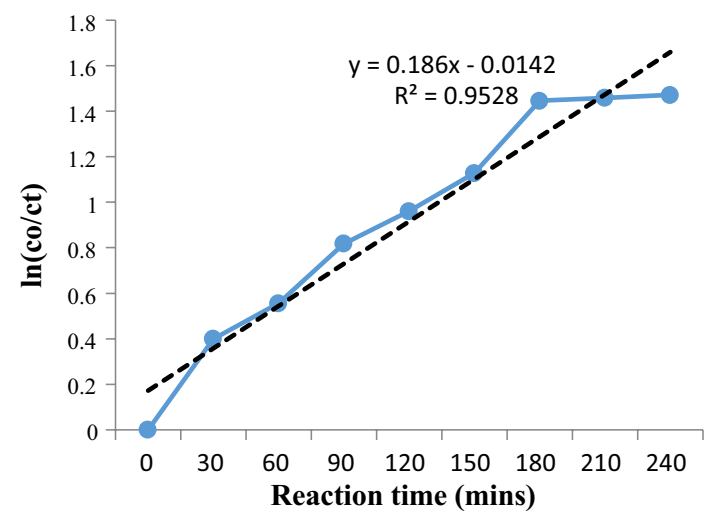

Fig. 5 Kinetics of C.O.D. removal in photo fenton after rotavapour distillation

The effluent from combined rotavapor distillation and photo fenton process was treated by using anaerobic biological treatment. The percentage removal of COD in biological process was 57\%. The overall percentage removal of COD has been increased to $95 \%$.

\section{Methodology 3: combined coagulation, Fenton, electro oxidation and anaerobic biological treatment for the treatment of pesticide intermediate industrial wastewater}

Initially, the sample with initial COD $90,000 \mathrm{mg} / \mathrm{l}$, was treated with coagulation in which, optimum \% removal of COD of $41 \%$ was obtained at an alum dosage of $0.25 \mathrm{~g}$, thereafter this effluent was treated by fenton in which COD removal of $35.6 \%$ was obtained at an optimum reaction time of 180 min (Figs. 6, 7). The overall percentage removal of COD was increased from $41 \%$ in coagulation to $62 \%$ in combined coagulation and fenton process. 


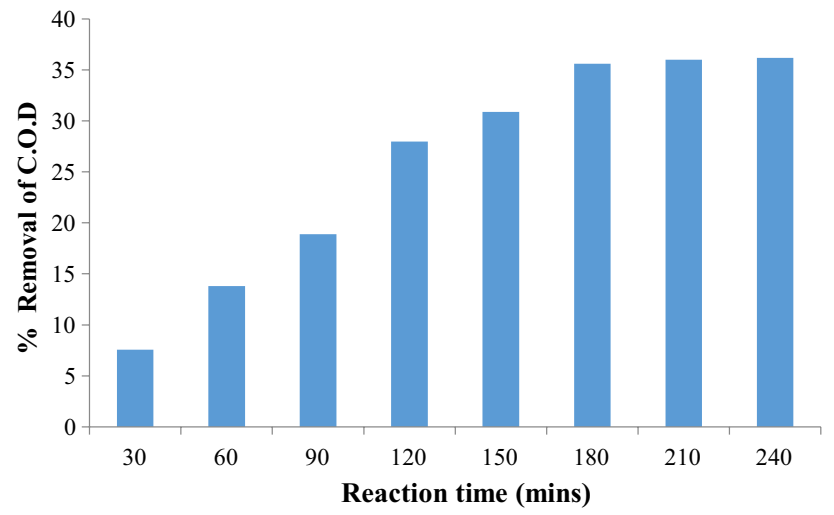

Fig. 6 Percentage removal of cod after combined coagulation and Fenton. Experimental conditions: $\mathrm{FeSO}_{4}$ concentration (mg/L): $0.04 \mathrm{~g}, \mathrm{H}_{2} \mathrm{O}_{2}$ concentration: $1.4 \mathrm{ml}, \mathrm{PH}: 3$, initial C.O.D: $52,800 \mathrm{mg} / \mathrm{L}$, working volume: $250 \mathrm{ml}$

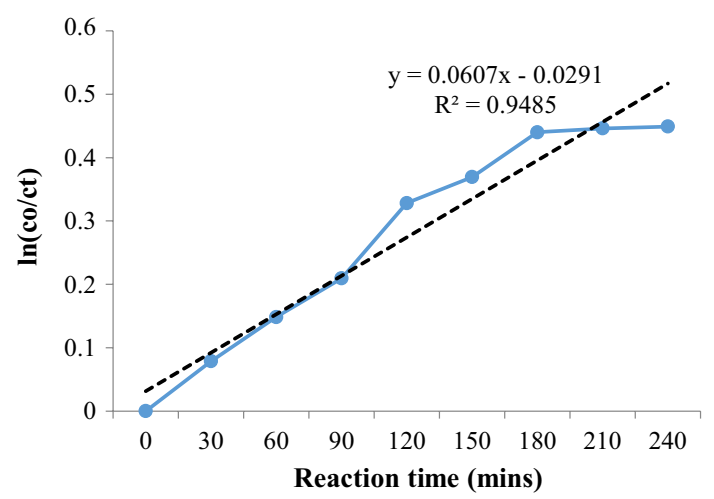

Fig. 7 kinetics of C.O.D removal in Fenton after coagulation

This combined coagulation and fenton treated sample was further treated by electro oxidation which resulted in a COD removal of $33 \%$ at an optimum reaction time of $50 \mathrm{~min}$ (Figs. 8, 9). The overall percentage removal of C.O.D. was increased from $62 \%$ in combined coagulation and Fenton process to $75 \%$ in combined coagulation, fenton process and electro oxidation.

Finally this effluent from combined coagulation, Fenton and electro oxidation process was treated by using anaerobic biological treatment. The percentage removal of COD in biological process was $12.44 \%$. The overall percentage removal of COD has been increased to $78.88 \%$.

\section{Comparison between above three methodologies}

From the Fig. 10, it was observed that the percentage removal of COD trend was methodology-2(95.77\%) followed by methodology-1(95\%). There exists only a slight difference in percentage removal of COD between methodology $1 \& 2$. As the photo fenton process in methodology-2

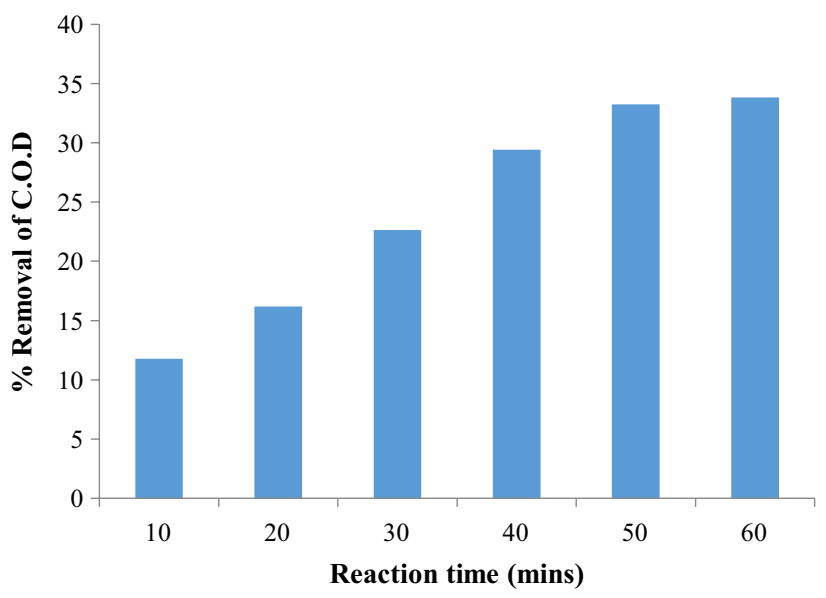

Fig. 8 Percentage removal of C.O.D after combined coagulation, Fenton and electro oxidation. Experimental conditions: working volume $=250 \mathrm{ml}$; electrode material $=\mathrm{SS}-\mathrm{SS}$, electrode distance $=1 \mathrm{~cm}$, reaction time $=10,20,30,40,50$ and $60 \mathrm{~min}$, initial $\mathrm{pH}=7$, electrode active surface area $=40 \mathrm{~cm}^{2}$, applied direct current voltage $=8 \mathrm{~V}$, Current $=4-6$ A, no. of electrodes $=2$

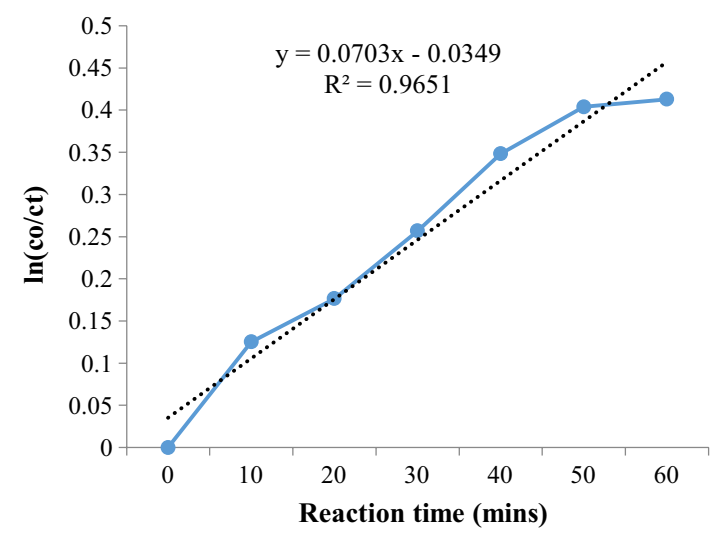

Fig. 9 Kinetics of C.O.D. removal in electro oxidation after coagulation and fenton

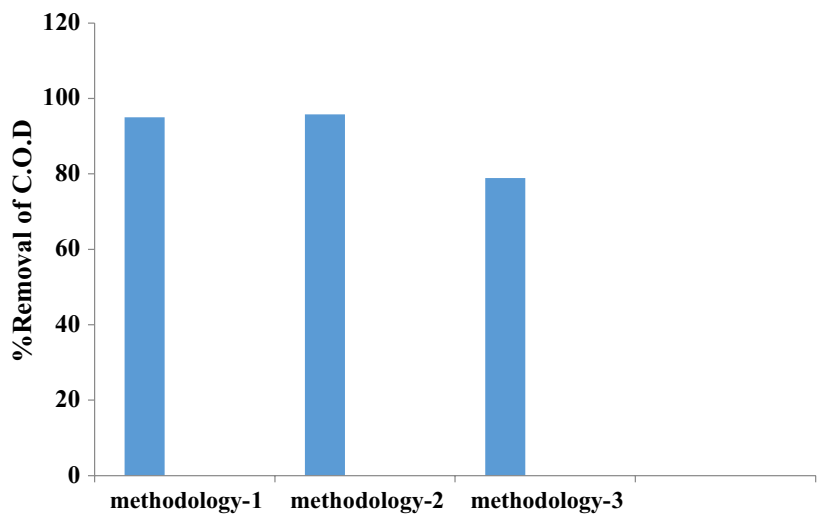

Fig. 10 Comparison of percentage removal of C.O.D by three methodologies used in this study 
Table $2 R^{2}$ and rate constants values of various treatment methods used for treating pesticide intermediate waster sample

\begin{tabular}{llll}
\hline S. no. & Sequential processes & $\begin{array}{l}\text { Rate } \\
\text { constant } K \\
\left(\mathrm{~min}^{-1}\right)\end{array}$ & $R^{2}$ \\
\hline Methodology 1 & Fenton after distillation & 0.144 & 0.90 \\
Methodology 2 & Photo Fenton after distillation & 0.186 & 0.95 \\
Methodology 3 & Fenton after coagulation & 0.060 & 0.94 \\
& $\begin{array}{l}\text { E.O. after coagulation and } \\
\text { Fenton }\end{array}$ & 0.070 & 0.96 \\
& & & \\
\hline
\end{tabular}

renders excess operational costs when compared to fenton process, methodology-1 can be preferred for the treatment of pesticide intermediate industrial wastewater.

\section{Kinetic analysis of C.O.D removal}

For fenton, photo fenton and electro oxidation processes, a plot has been drawn between the values of $\ln \left(C_{0} / C_{\mathrm{t}}\right)$ and the reaction time. Least square regression was used to calculate the $k$ and $R^{2}$ values for each method (Pinto et al. 2018; Jotin et al. 2012; Lafi and Al-Qodah 2006) and the values thus obtained were mentioned in Table 2. As the values of $R^{2}$ obtained were high, it can be stated that the applied model fits successfully for the above methods (Alalma and Tawfika 2015). From the kinetic analysis it can be concluded that the reactions in above methods follows pseudo-first order kinetics.

The relation between the residual concentration of pollutant and the reaction time in pseudo first order equation (Alalma and Tawfika 2015) can be given by:

$-\mathrm{d} C / \mathrm{d} t=k * C$

Upon integrating Eq. (1):

$\ln C_{0} / C=k * t$

where $k=$ the constant reaction rate, $C_{0}=$ the initial concentration of target pollutant in aqueous solution, and $C=$ the residual concentration of pollutant at time $t$.

\section{Conclusions}

1. Among the three sequential methodologies opted in this study for the treatment of pesticide intermediate industrial wastewater, methodology-2 (combined rotavapor distillation, photo fenton and anaerobic biological treatment) resulted in highest percentage removal of C.O.D $(95.77 \%)$.
2. In methodology-1 (combined rotavapor distillation, fenton and anaerobic biological treatment) percentage removal of C.O.D was $95 \%$, which was very slightly less than the percentage removal of C.O.D. in methodology- 2 .

3. Therefore in-order to avoid excess operational costs of photo fenton process when compared to fenton process, methodology-1(combined rotavapor distillation, fenton and anaerobic biological treatment) can be preferred for the treatment of pesticide intermediate industrial wastewater.

Funding The research leading to these results received funding fromDepartment of Science and Technology (DST-WTI), Ministry of Science and Technology, Government of India/Bharat Sarkar, under Grant Agreement NoDST/TM/WTI/2K16/220. One of the authors Dr. D Bhagawan received research support from University Grants Commission (UGC), Government of India/Bharat Sarkar with Grant Order No. F./31-1/2017/PDFSS-2017-18-TEL-14164.

\section{Compliance with ethical standards}

Conflict of interest All authors have seen and approved the manuscript being submitted. Hence, on behalf of all authors, the corresponding author states that there is no conflict of interest.

Informed consent Informed consent was obtained from all individual authors or persons involved in the study.

Open Access This article is licensed under a Creative Commons Attribution 4.0 International License, which permits use, sharing, adaptation, distribution and reproduction in any medium or format, as long as you give appropriate credit to the original author(s) and the source, provide a link to the Creative Commons licence, and indicate if changes were made. The images or other third party material in this article are included in the article's Creative Commons licence, unless indicated otherwise in a credit line to the material. If material is not included in the article's Creative Commons licence and your intended use is not permitted by statutory regulation or exceeds the permitted use, you will need to obtain permission directly from the copyright holder. To view a copy of this licence, visit http://creativecommons.org/licenses/by/4.0/.

\section{References}

Alalma MG, Tawfika A (2015) Comparison of solar $\mathrm{TiO}_{2}$ photocatalysis and solar photo-Fenton for treatment of pesticides industry wastewater: operational conditions, kinetics, and costs. J Water Process Eng J. https://doi.org/10.1016/j.jwpe.2015.09.007

Barbusiński K (2015) Toxicity of industrial wastewater treated by Fenton's reagent. Pol J Environ Stud 14(1):11-16

Bhagawan D, Poodari S, Chaitanya N, Ravi S, Rani YM, Himabindu V, Vidyavathi S (2017) Industrial solid waste landfill leachate treatment using electrocoagulation and biological methods. Desalin Water Treat 68:137-142

Boczkaj G, Gągol M, Klein M, Przyjazny A (2018) Effective method of treatment of effluents from production of bitumens under basic 
$\mathrm{pH}$ conditions using hydrodynamic cavitation aidedby external oxidants. Ultrason Sonochem 40:969-979

Carlosa M (2008) Removal of the pesticide methamidophos from aqueous solutions by electrooxidation using $\mathrm{Pb} / \mathrm{PbO}_{2}, \mathrm{Ti} / \mathrm{SNO}_{2}$, and $\mathrm{Si} / \mathrm{BDD}$ electrodes. Environ Sci Technol 42:18

Chen S, Sun D, Chung JS (2007) Treatment of pesticide wastewater by moving bedbiofilm reactor combined with Fenton-coagulation pretreatment. J Hazard Mater 144:577-584. https://doi.org/10. 1016/j.jhazmat.2006.10.075

De Smedt F, Ferrer K, Leus PS (2015) Removal of pesticides from aqueous solutions by adsorption on zeolites as solid adsorbents. Adsorp Sci Technol 33:457-485

Fenoll J, Flores P, Hellín P, Martínez CM, Navarro S (2012) Photo degradation of eight miscellaneous pesticides in drinking water after treatment with semiconductor materials under sunlight at pilot plant scale. Chem Eng J 204-206:54-64. https://doi.org/10. 1016/j.cej.2012.07.077

Grötzner M, Melchiors E (2018) Pulp and paper mill effluent treated by combining coagulation-flocculation-sedimentation and fenton processes. Water Air Soil Pollut 229, Article number: 364

Haaz E, Fozer D (2019) Vacuum evaporation and reverse osmosis treatment of process wastewaters containing surfactant material: COD reduction and water reuse. Clean Technol Environ Policy 21:861-870

Jhoshi SM, Gogate PR (2016) Intensification of industrial wastewater treatment using hydrodynamic cavitation combined with advanced oxidation at operating capacity of $70 \mathrm{~L}$. Ultrason Sonochem 52(375):381

Jotin R, Ibrahim S, Halimoon N (2012) Electro coagulation for removal of chemical oxygen demand in sanitary landfill lechate. Int J Environ Sci 3(921-930):2

Lafi WK, Al-Qodah Z (2006) Combined advanced oxidation and biological treatment processes for the removal of pesticides from aqueous solutions. J Hazard Mater 137:489-497. https://doi.org/ 10.1016/j.jhazmat.2006.02.027

Lapertot M, Ebrahimi S (2007) Photo-Fenton and biological integrated process for degradation of a mixture of pesticides. J Photochem Photobiol A 186:34-40

Malato S, Blanco J (2002) Photocatalytic treatment of water-soluble pesticides by photo-Fenton and $\mathrm{TiO} 2$ using solar energy. Catal Today 76:209-220

Mohadesi M, Shokri A (2019) Treatment of oil refinery wastewater by photo-Fenton process using Box-Behnken design method: kinetic study and energy consumption. Int J Environ Sci Technol 16:7349-7356

Navarro S, Fenoll J, Vela N, Ruiz E, Navarro G (2011) Removal of ten pesticides from leaching water at pilot plant scale by photo-Fenton treatment. Chem Eng J 167:42-49. https://doi.org/10.1016/j.cej. 2010.11.105

Pinto HB, de Souza BM (2018) Treatment of a pesticide industry wastewater mixture in a moving bed biofilm reactor followed by conventional and membrane processes for water reuse. https://doi. org/10.1016/j.jclepro.2018.08.113

Rhind SM (2002) Endocrine disrupting compounds and farm animals: their properties, actions and routes of exposure. Domest Anim Endocrinol 23(1-2):179-187. https://doi.org/10.1016/S07397240(02)00155-8

Sadeghi S, Alavi Moghaddam MR, Arami M (2013) Improvement of electrocoagulation process on hexavalent chromium removal with the use of polyaluminum chloride as coagulant. Desal Water Treat 52:1-12. https://doi.org/10.1080/19443994.2013.814328

Thangamani R, Muthusamy M, Manickam P, Periyaraman A (2012) Advance electrochemical oxidation of fipronil contaminated wastewater by graphite anodes and sorbent nano hydroxyapatite. Energy Sources A Recov Util Environ Effects 41:866-880

Valickova M, Derco J, Simovicova K (2013) Removal of selected pesticides by adsorption. Acta Chim Slov 6:25-28

Vijaya Krishna S, Kiran Kumar P, Chaitanya N, Bhagawan D, Himabindu V, Lakshmi Narasu M (2017) Biohydrogen production from brewery effluent in a batch and continuous reactor with anaerobic mixed microbial consortia. Biofuels 8(6):701-707. https://doi.org/ $10.1080 / 17597269.2016 .1206409$

Wong JM (2004) Treatment of pesticide industry wastes. In: Wang LK, Hung Y-T, Lo HH, Yapijakis C (eds) Handbook of industrial and hazardous wastes treatment. CRC Press, Boca Raton, pp 1005-1049. https://doi.org/10.1201/9780203026519.ch22

Zhang M-H, Dong H (2019) A review on Fenton process for organic wastewater treatment based on optimization perspective. Sci Total Environ 670:110-121. https://doi.org/10.1016/j.scitotenv.2019.03. 180

Publisher's Note Springer Nature remains neutral with regard to jurisdictional claims in published maps and institutional affiliations.

1 